\title{
Tree-ring variation in teak (Tectona grandis L.) from Allapalli, Maharashtra in relation to moisture and Palmer Drought Severity Index, India
}

\author{
Somaru Ram*, H P Borgaonkar, A A Munot and A B Sikder \\ Indian Institute of Tropical Meteorology, Pune 411 008, India. \\ *e-mail:somaru@tropmet.res.in
}

\begin{abstract}
We developed a ring-width chronology of teak (Tectona grandis L.) from a moisture stressed area in Maharashtra, India. Bootstrapped correlation analysis indicated that moisture index (MI) and Palmer Drought Severity Index (PDSI) showed better performance rather than same year rainfall over the region. Tree-ring variations were most correlated positively with PDSI during different seasons compared with MI. Significant strong positive correlation with MI, and negative association with temperature and potential evapotranspiration (PET) were found during previous and current year post-monsoon (ON). This study shows that the moisture availability during the post-monsoon of the previous year has a significant role in the development of annual growth rings. The reconstructed previous year post-monsoon $(-\mathrm{ON})$ moisture index for the period 1866-1996 indicates 3.5 and 29.3 years periodicities.
\end{abstract}

\section{Introduction}

Tropical tree-ring studies have been increasingly pursued over the past, and with increasingly greater success (Buckley et al 1995, 2001, 2005, 2007; D' Arrigo et al 1994, 1997, 2006; Pumijumnog et al 1995). Much of the interest is driven by the need to understand the role of tropics in our changing global climate, where tree-rings can be used as one proxy source of terrestrial climate. In spite of these successes, however, tropical tree-ring research is still fraught with difficulties that arise from many sources, including unclear ring boundaries for many species in spite of environmental conditions that induce dormancy and nebulous seasonality in some regions (for example, areas influenced by both northeast and southwest monsoon rains, such as parts of Sri Lanka and Philippines).
Moreover, Tree-ring chronologies have been developed and used by many tree-ring scientists to reconstruct relatively local temperature and precipitation histories at various locations in India (Pant and Borgaonkar 1984; Borgaonkar et al 1994, 1996; Bhattacharyya and Yadav 1999; Singh et al 2009).

However, besides these, in peninsular India, where both the southwest (SW) and northeast (NE) monsoons are prominent, Bhattacharyya et al (2007) showed that NE monsoon precipitation (i.e., October and November) has a significant role in controlling the development of mean vessel area of teak in Kerala. Teak has been widely analysed and is suitable for environmental and climatic analysis (Bhattacharyya et al 1992; Pumijumnong et al 1995; Yadav and Bhattacharyya 1996; Shah et al 2007; Managave et al 2010). The annual

Keywords. Palmer Drought Severity Index (PDSI); moisture index; annual tree-rings; precipitation; temperature; post-monsoon. 
variations in teak growth in central India have been demonstrated (Ram et al 2008, 2010) and found to be highly influenced by the moisture index. Pant and Borgaonkar (1983) also revealed the response of teak to rainfall in the rainy season for India. However, in this paper, an attempt has been made to investigate dendroclimatic potential of teak (Tectona grandis L.) from the central part of India, and any significant relationship existing between climate and a tree-ring chronology of teak from Allapalli, Maharashtra.

\section{Tree-ring data}

Tree-ring width data of about 40 tree core samples of teak from Allapalli $\left(19^{\circ} 25^{\prime} 12^{\prime \prime} \mathrm{N} ; 80^{\circ} 4^{\prime} 11^{\prime \prime} \mathrm{E}\right)$ site of central India have been used for the present study (figure 1). All cores were surfaced by polishing with sand paper so that the surface of the rings can be rendered visible. Samples were dated using the traditional skeleton plotting technique (Stokes and Smiley 1968). All samples were microscopically examined at various stages of processing, cross-matching and examination of anatomical details of anomalous rings to detect false and double rings. Ring-width of each core sample was measured with an accuracy of $10^{-3} \mathrm{~cm}$. Ringwidth series were rechecked using computer program COFECHA (Holmes 1983) for possible measurement or dating errors. This involves statistical cross-dating to test each individual series against a master chronology (mean of all series) on the basis of correlation coefficients.

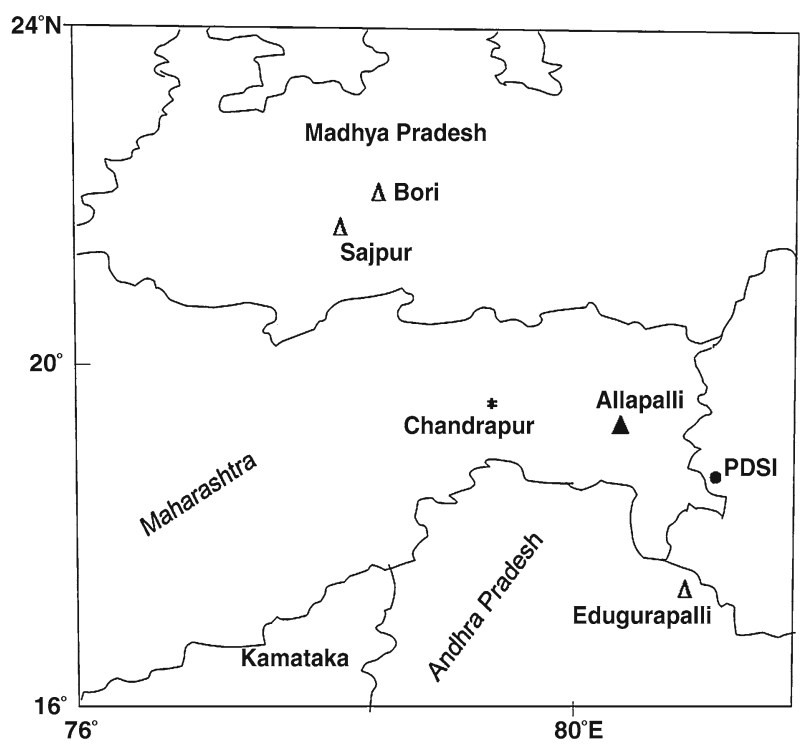

Figure 1. Locations of tree-ring sampling site and meteorological station: $\Delta$ : tree-ring sites; $\boldsymbol{\Lambda}$ : present study area; *: meteorological station; •: PDSI.
Both un-detrended and detrended mean ringwidth series are shown in figure 2, the smoothed line is 30 years cubic spline fit in upper panel, representing the nature of ring-width series of teak tree with the cubic spline filter. The dated ringwidth measurement series were detrended by using software ARSTAN (Holmes et al 1986; Cook et al 1990), which removes the biological growth trend of age related as well as other low frequency variations due to stand dynamic features such as forest fires and insect epidemics and maximize the climatic information in the series. The options, cubic smoothing spline with a $50 \%$ frequency response cut-off equal to $2 / 3$ of the series length were used for detrending, to remove varying proportions of low-frequency variance in all series. The indices for each series were derived by taking the ratio of the measurement over the fitted value in each year, producing dimensionless indices with a mean of 1.0. These indices were then prewhitened using an autoregressive model selected on the basis of Akaike Information Criterion and combined across all series in each year using biweight robust estimation of the mean to discount the influence of outliers. A set of three chronologies, standard, residual containing only the high-frequency variations and an arstan composed of the residual reincorporated with the polled autoregression was developed using the computer program ARSTAN. The resulting tree-ring chronology represents growth variations caused by common environmental forcing to climate (figure 2).

For comparison purposes, we have also shown in figure 1 sites of other recently published teak tree chronologies (Ram et al 2008) from distinct

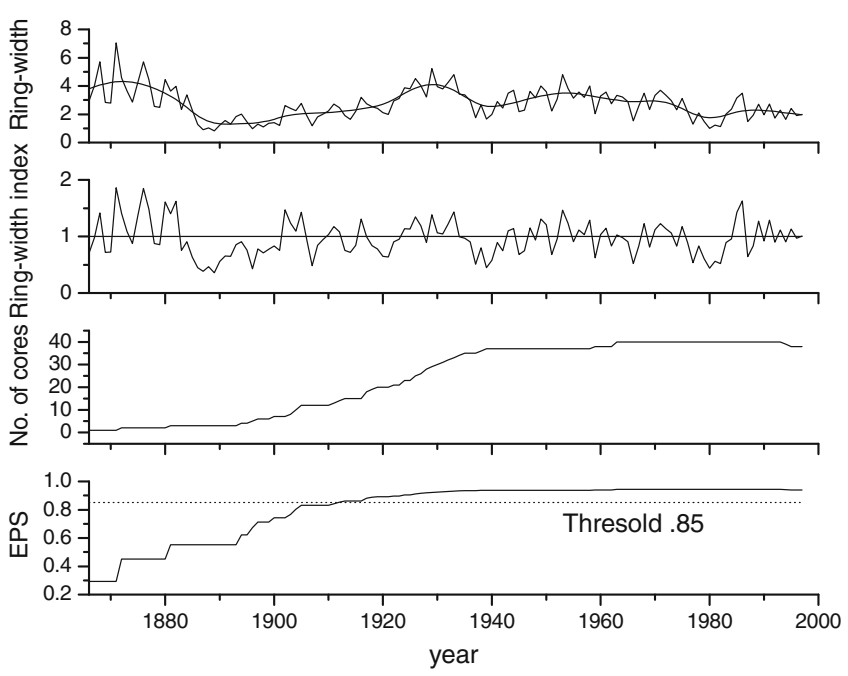

Figure 2. Mean (un-detrended) ring-width series and ringwidth index of teak from Allapalli along with numbers of cores and expressed population signal (EPS). Smooth line is 30 years cubic spline fit (upper panel). 
places of central India. These chronologies revealed good association with the present chronology of Allapalli. The correlation coefficient between the present chronology of Allapalli and the published chronologies of central India (Ram et al 2008) is 0.20 during 1887-1997 which is significant at 5\% level. Moreover, the general weakness of correlation between chronologies is not entirely surprising, given the large distance between many pair of sites and ecological conditions. In addition, it is likely that there was a wide range of ecological conditions and site histories in and around the sampling sites, which might mask the common climate influences in teak tree-ring chronologies. However, records of weaker correlations during some periods show the existence of site specific variations. Ramesh et al (1989) also indicated that the trees at different locations are controlled by cumulative effect of other parameters, such as the position of the trees, gravity stress, local effect and a variety of other metabolic factors.

Ring-width chronology statistics such as mean sensitivity, standard deviation, expressed population signal (EPS), and signal-to-noise ratio (SNR) are shown in table 1. Mean sensitivity is a measure of relative difference in ring-width from one ring to next ring (Fritts 1976). High value of mean sensitivity is desirable for ring-width series as it indicates the presence of high-frequency variance (Fritts 1976). Autocorrelation is the association between ring-width for the year $(t-1)$ and the subsequently formed ring $t, t+1$, to $t+k$. In this chronology, this value is moderate $(0.42)$, which indicates that some persistent trend exists in the present chronology. EPS is a measure of the correlation between the mean chronology derived from the core samples and population from which they are drawn (Wigley et al 1984). A value of 0.85 was put forward as a reasonable threshold. SNR and EPS show the usefulness of the chronology for past climate reconstruction (Wigley et al 1984).

Table 1. Selected statistics of tree-ring chronology of Tectona grandis L. at Allapalli.

\begin{tabular}{ll}
\hline Chronology time span & AD 1866-1997 \\
Numbers of tree (radii) & $23(40)$ \\
Mean sensitivity & 0.27 \\
Standard deviation & 0.30 \\
Autocorrelation order1 & 0.42 \\
Common interval time span & $1936-1997$ \\
Number of trees (radii) & $20(32)$ \\
Mean correlation among all radii & 0.30 \\
Mean correlation between trees & 0.29 \\
Signal-to-noise ratio (SNR) & 8.1 \\
Expressed population signal (EPS) & 0.89 \\
\hline
\end{tabular}

Strength of signal between trees (common variance) was computed by calculating the signal-tonoise ratio (Wigley et al 1984). The common variance is a mean of the correlation coefficients of all possible pairwise combinations of the ring-width index series over the common interval period. This value indicates the variance due to the common forcing factor having significant role in limiting the growth of trees. A tree-ring chronology along with sample size and the expressed population signal are presented in figure 2. We used the standard chronology in climate modelling and reconstruction studies presented here.

\section{Climate data}

The climate data (mean monthly temperature and precipitation) close to the tree-ring sampling site, are available from Chandrapur. The southwest monsoon brings most of the rainfall during the year in this region whereas northeast monsoon is negligible. About $75 \%$ of the annual rainfall is contributed during monsoon (June-September). Monsoon season receives the highest rainfall $(1136.2 \mathrm{~mm})$ while northeast monsoon gives the least rainfall $(68.4 \mathrm{~mm})$. On an average, July is the wettest $(378.4 \mathrm{~mm})$, and May is the hottest $\left(35.5^{\circ} \mathrm{C}\right)$ month (figure 3$)$. Annual average rainfall is $1295 \mathrm{~mm}$.

A regional series of MI which is a function of rainfall and temperature, and potential evapotranspiration (PET) of central India $\left(18^{\circ}\right.$ to $23^{\circ} \mathrm{N} ; 77^{\circ}$ to $\left.83^{\circ} \mathrm{E}\right)$, prepared earlier by Ram et al (2008), has also been used for the present study of tree-growth climate relationship between MI and tree-ring index chronology of Allapalli. We also compared the tree-ring chronology with the updated $2.5 \times 2.5$ gridded global monthly Palmer Drought Severity Index (PDSI) data from Dai et al (2004). PDSI is a metric of drought that takes into

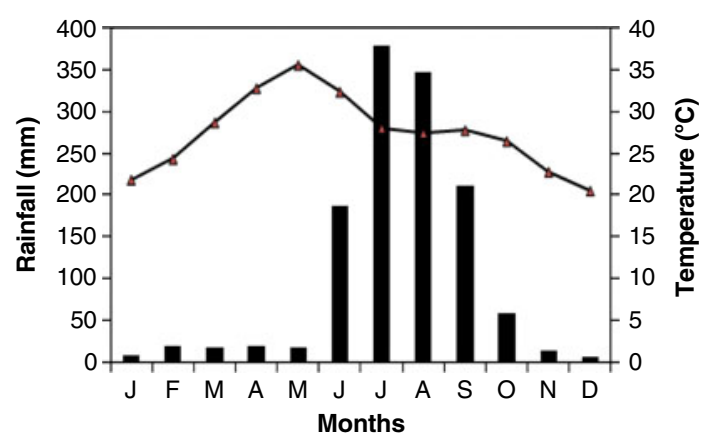

Figure 3. Mean monthly variation of precipitation (bars) and mean surface temperature (solid line) at Chandrapur during period 1901-2000. 
account temperature and precipitation and is considered to be a proxy for soil moisture (Palmer 1965). In this paper, an attempt has been made to identify wet and dry conditions in India using PDSI. For this purpose we have considered the nearest grid point $(18.75 \mathrm{~N}, 81.25 \mathrm{E} ; 1870-2004)$ in the present study as shown in figure 1 .

\section{Tree growth-climate relationship}

The standard ring-width chronology index was correlated with seasonal climatic variables to pool the common climatic signal in tree growth. The seasons are, previous monsoon (-JJAS), previous postmonsoon (-ON), winter (DJF), spring (MAM), monsoon (JJAS), post-monsoon (ON) and annual. Climate growth response has been analyzed for the common period 1901-1997, using Bootstrapped correlation analysis in Dendro-Clim 2002 developed by Biondi and Waikul (2004). Dendro-Clim 2002 uses 1000 Bootstrapped samples (drawn at random with replacement) to compute a median correlation coefficient for each seasonal variable. The median coefficient is considered to be significant at $5 \%$ level if its absolute value exceeds half the difference between the 97.5th and 2.5th quantile of the 1000 samples (Biondi and Waikul 2004). The results are shown in table 2 .

In case of temperature, the correlation coefficient between tree-ring index and temperature showed significant negative relationship during previous and current year of post-monsoon (ON) (table 2). Higher temperature cause increased evaporation and evapotranspiration, which reduces soil moisture availability during subsequent growing season. In addition, higher temperature can be limiting to both photosynthesis and respiration (Fritts 1976). The optimum temperature for net photosynthesis may also vary throughout the season, and from site to site, depending on prior light intensities, moisture availability which precondition the tree (Fritts
1976). The increased temperature might enhance PET, showing negative relationship with annual tree-growth during previous and current year of post-monsoon $(\mathrm{ON})$, which is statistically significant at $1 \%$ level (table 2). It means that higher temperature during post-monsoon $(\mathrm{ON})$ is not found to be conducive for tree-growth at Allapalli site.

As there is a strong positive relationship between tree-ring width variations and moisture index (which is an integration of precipitation and mean temperature) during previous and current year of post-monsoon, the moisture index (MI) is dominant climatic signal (table 2). But, MI rather than rainfall showed better performance with tree-ring index chronology over the region during previous year post-monsoon $(-\mathrm{ON})$. MI explains more variance in annual tree growth than rainfall and PDSI. The moisture availability at the beginning of the growing season might have important role in the development of annual growth rings over central India (Ram et al 2010), indicating positive relationship between tree-ring chronologies and winter MI. Ram et al (2008) have also shown earlier that the positive relationship between tree-growth and MI of prior year post-monsoon which is barely significant at $5 \%$ level besides monsoon season. MI index during post-monsoon of prior season play an important role in the growth of teak trees in central India. The present study also shows the significant positive relationship between tree-ring width variations and MI as well as the PDSI during postmonsoon (table 2). This result suggests that the soil moisture availability at the end of monsoon season plays a vital role in tree-growth processes as supported by Pant and Borgaonkar (1983) and Buckley et al (2007). Loss or accumulation of soil moisture is a precondition for the coming growing season (Palmer 1965). Moreover, the increased soil moisture at the beginning of the dry season also carryover effects in the physiological processes of the tree (Fritts 1976).

Table 2. Correlation coefficients between tree-ring index chronology and rainfall (RF), temperature (TM), Palmer Drought Severity Index (PDSI), regional moisture index (MI) and potential evapotranspiration (PET) during different seasons for Allapalli (1901-1997).

\begin{tabular}{lrrrrrrr}
\hline & - JJAS & - ON & DJF & MAM & JJAS & ON & Annual \\
\hline RF & -0.149 & 0.117 & -0.039 & -0.120 & 0.016 & 0.076 & 0.011 \\
TM & 0.054 & $-0.22^{*}$ & -0.078 & 0.104 & 0.032 & $-0.21^{*}$ & -0.036 \\
PDSI & 0.130 & $0.21^{*}$ & $0.21^{*}$ & $0.20^{*}$ & $0.20^{*}$ & $0.24^{*}$ & $0.23^{*}$ \\
MI & -0.10 & $0.30^{* *}$ & 0.03 & -0.10 & 0.01 & $0.21^{*}$ & 0.02 \\
PET & 0.03 & $-0.26^{* *}$ & -0.09 & 0.06 & 0.04 & $-0.37^{*}$ & -0.01 \\
\hline
\end{tabular}

* Significant at $5 \%$ level.

** Significant at $1 \%$ level. 
However, the correlation between the present chronology and precipitation and MI of monsoon months are weak, showing neither precipitation nor MI of monsoon season (JJAS) is limiting tree growth at Allapalli site. The role of significant months/seasons of climatic variables on the growth may not be common to each site. It might be due to site-specific variations and other local factors which are not dealt here.

PDSI also reveals significant positive relationship with a tree-ring index during different seasons except previous year monsoon (table 2). However, these results are not surprising because in this technique, rainfall, evapotranspiration, soil moisture, climate of the area, current and antecedent weather are taken into account for involving a drought index (Palmer 1965). Therefore, all seasons reveal a significant positive relationship with tree-ring index during different seasons. As shown in table 2, the correlations are significant at 5\% level. This is a clear indication of the effects of soil moisture on teak growth; the PDSI is most suitable for describing soil moisture (Dai et al 2004). Ram et al (2011) also revealed the significant positive relationship between tree-ring index chronology and PDSI during different seasons indicating moisture sensitive tree-growth in south India. Positive PDSI values indicate wetter conditions, while negative values indicate dryer conditions, PDSI has the ability to detect and quantify dry and wet conditions across space and time (Alley 1984; Keyantash and Dracup 2002; Borgaonkar et al 2010). The significant positive relationship of tree-ring index chronology with PDSI indicates moisture dependence of tree-growth.
Regional moisture index also show strong positive relationship with tree-ring index during previous year post-monsoon $(-\mathrm{ON})$, which is statistically significant at $1 \%$ level. This relationship is stronger between moisture index and treering index on a decadal scale after fitting a cubic spline smoothing (figure $4 \mathrm{a}, \mathrm{b}$ ). Smooth lines in figure $4(\mathrm{a}, \mathrm{b})$ are the low-pass filter based on the cubic spline smoothing at 50\% VRF (variance reduction frequency) of 10 years. During 1902-1997, the correlation coefficient is 0.50 . The low frequency variations show almost similar pattern of MI and tree-ring index on decadal scale (figure 4a, b). Regional moisture index might be more responsible to annual tree-rings than local climate as recorded by Ram et al $(2008,2010)$. Sometimes, local climate also became more prominent than regional signals as recorded by Bhattacharyya et al (1992). Moreover, ring-width index revealed a strong positive association with moisture index since late 20th century. The correlation coefficient between ring-width index and moisture index is 0.65 which is highly significant at $0.1 \%$ level (figure 4a, b). MI may be an appropriate climate parameter to reconstruct from tree-ring width chronology. It is also inferred that the 20th century was the warmest during the past 1000 years, with AD 1989-1998 and 1998 being the warmest decade and year respectively. And, both moisture index and tree-ring index showed very similar pattern during recent decades (figure 4a, b). Ram et al (2010) also showed a strong positive association with moisture index during late 20th century over central India. However, table 2 shows insignificant correlation between rainfall and tree-ring
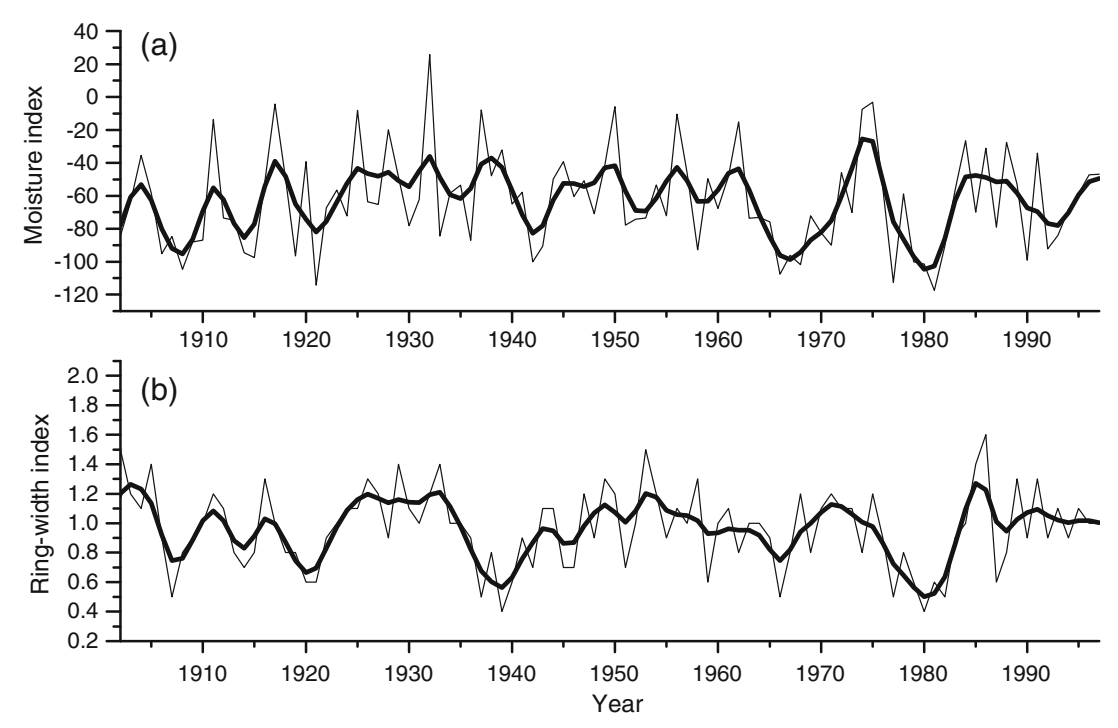

Figure 4. (a) Time series of the previous year post-monsoon (-ON) moisture index for the period 1902-1997. (b) Time series of ring-width index for the period 1902-1997. Dark smooth lines represent low frequency variations. 
Table 3. Calibration-verification statistics based on principal component regression analysis in which tree-ring records are used as predictors for post-monsoon moisture index.

\begin{tabular}{lccccccc}
\hline \multicolumn{3}{c}{ Calibration } & & \multicolumn{4}{c}{ Verification } \\
\cline { 5 - 7 } \cline { 5 - 7 } Period & $\mathrm{R}$ & Adjusted $\mathrm{r}^{2}$ & & Period & $\mathrm{r}$ & Pmt & $\mathrm{RE}$ \\
\hline $1902-1925$ & $0.58^{* *}$ & $0.19^{*}$ & & $1926-1996$ & $0.23^{*}$ & $2.35^{*}$ & $0.080^{*}$ \\
$1926-1996$ & $0.24^{*}$ & $0.024^{*}$ & & $1902-1925$ & $0.40^{*}$ & 0.784 & 0.104 \\
$1902-1996$ & $0.40^{* *}$ & $0.087^{*}$ & & & & & \\
\hline
\end{tabular}

$\mathrm{R}$ : the multiple correlation coefficients, adjusted $\mathrm{r}^{2}$ : the square of the correlation coefficient adjusted for the loss of degree of freedom, r: the correlation coefficient calculated between actual and estimated data, Pmt: the value derived using the product mean test, and RE: the reduction of error.

* Significant at $5 \%$ level. ** Significant at $1 \%$ level.

variations. It is a valuable proxy for moisture index. The present study is based on chronology at a single site in conjunction with Ram et al (2008).

\section{Reconstruction of MI}

The coherent relationship noted between moisture index and chronology enabled us to reconstruct moisture index. Tree-ring chronology prepared from a single site in Maharashtra has shown significant relationship with climatic factors. The strong relationship noted between the ring-width chronology and previous year post-monsoon (-ON) moisture index has been exploited to reconstruct moisture index back to AD 1866. Reconstructing spatial patterns of moisture index from tree rings has been done using a variety of statistical method developed by Cook et al (1999, 2004). We used tree-ring data for years $t, t-1, t+1$ and $t+2$ in a principal component regression analysis to estimate post monsoon $(\mathrm{ON})$ moisture index for the year $t-1$. The first principal component $(\mathrm{PC} 1)$ with eigenvalue $>1$ explained $49 \%$ of the common variance retained, demonstrating the strong common signal in the first PC1 and its fidelity in developing reconstruction. To explore the temporal stability in ring-width index and previous year post-monsoon moisture index $(-\mathrm{ON})$, crosscalibrations were performed in two split periods (Briffa et al 1988). For this purpose, the mean moisture index series was split in two sub-periods: 1902-1925 and 1926-1996. Although the calibration for the second sub-period is slightly weaker than the first, both models yielded significant statistics as measured by various tests of similarity
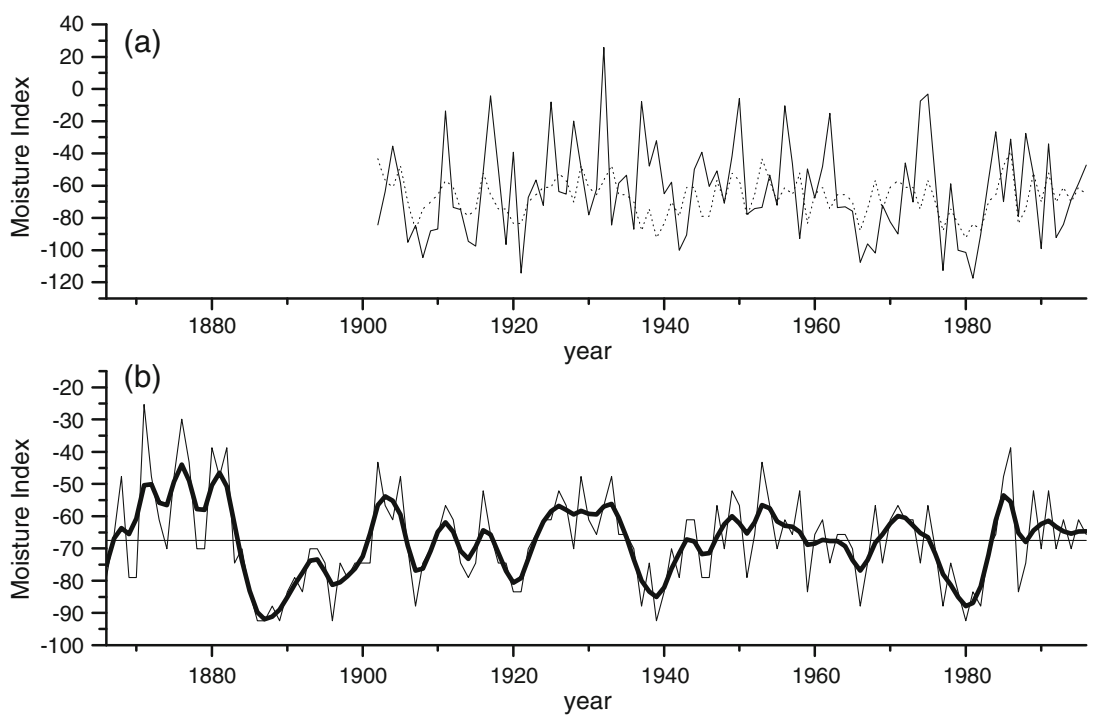

Figure 5. (a) Actual moisture index (solid line) and reconstructed previous year post-monsoon (-ON) moisture index (dashed line). (b) Reconstructed previous year post-monsoon (-ON) moisture index back to AD 1866. The superimposed smooth line over the reconstruction is low-pass filtered to emphasize the fluctuations. 
(Fritts 1976). The results of calibration and verification periods are shown in table 3 . The first calibration model is superior; the model verified significant correlation, product mean test (Pmt), and reduction of error (RE) statistics (table 3, Fritts 1976). The second calibration model showed slightly less than the first. But both Pmt and RE are barely significant. However, any positive value of $\mathrm{RE}$ demonstrates skill in reconstruction (Fritts 1976; Cook et al 1994). These test results demonstrate the validity of our reconstruction model. However, to capture a higher portion of the low frequency variability in the final reconstruction, the entire period moisture index data were used to develop a calibration model, which capture $16 \%$ of the variance in the instrumental data during 19021996 (table 3). The comparison between reconstructed and instrumental data showed very close similarity (figure 5a), which is highly significant at $0.1 \%$ level.

\section{Discussion and conclusions}

The reconstruction of previous year post-monsoon $(-\mathrm{ON})$ moisture index back to AD 1866 are shown

Table 4. A simple matching of drought year in India and corresponding years ring-width index and reconstructed postmonsoon (-ON) MI.

\begin{tabular}{|c|c|c|}
\hline $\begin{array}{l}\text { Drought } \\
\text { year }\end{array}$ & $\begin{array}{l}\text { Ring-width } \\
\text { indices }\end{array}$ & $\begin{array}{c}\text { Reconstructed } \\
\text { post-monsoon } \\
\quad(-\mathrm{ON}) \mathrm{MI}\end{array}$ \\
\hline $1868^{*}$ & 1.414 & -47.7 \\
\hline $1873^{*}$ & 1.085 & -61.1 \\
\hline $1876^{*}$ & 1.847 & -29.8 \\
\hline $1877^{*}$ & 1.481 & -43.2 \\
\hline 1896 & 0.427 & -92.3 \\
\hline 1897 & 0.779 & -74.5 \\
\hline 1907 & 0.481 & -87.9 \\
\hline $1911^{*}$ & 1.170 & -65.5 \\
\hline 1918 & 0.836 & -74.5 \\
\hline 1920 & 0.649 & -83.4 \\
\hline 1941 & 0.893 & -70.4 \\
\hline 1951 & 0.679 & -78.9 \\
\hline 1965 & 0.908 & -70.0 \\
\hline 1966 & 0.520 & -87.9 \\
\hline $1972^{*}$ & 1.137 & -61.1 \\
\hline 1974 & 0.824 & -74.5 \\
\hline 1979 & 0.603 & -83.4 \\
\hline 1982 & 0.517 & -87.9 \\
\hline $1985^{*}$ & 1.424 & -47.7 \\
\hline $1986^{*}$ & 1.629 & -38.7 \\
\hline 1987 & 0.645 & -83.4 \\
\hline
\end{tabular}

*Drought years not matching with reconstructed postmonsoon MI. in figure 5(b). The smooth line superimposed on the reconstruction curve shows 10-year filtered values to emphasize to decadal-scale fluctuations. The reconstructed climate data reveals that there are several alternative periods of low and high moisture episodes. Among these, AD 1884-1900, 1906-1909, 1913-1915, 1918-1922, 1936-1946, 1959-1968, 1976-1983; AD 1867-1883, 1901-1905, 1910-1912, 1916-1917, 1923-1935, 1947-1958, 1969-1975, 1984-1996 are low and high moisture availability years respectively. Further to check the validity of the reconstructed series of the previous year post-monsoon $(-\mathrm{ON})$ moisture index $(\mathrm{AD}$ 1866-1996), it has been compared with years of principal drought over India (Mooley and Pant 1981; Munot 1998). A simple matching drought years of India and corresponding years ring-width index and reconstructed moisture index are in shown in table 4. All is synchronized with the years of both reduced tree growth and moisture index except eight principal drought years AD 1868, 1873, 1876, 1877, 1911, 1972, 1985 and 1986 defined earlier (Mooley and Pant 1981; Munot 1998) and are shown in table 4. Similarly, the aridity reported during 1884-1890 in southern India based on magnetic susceptibility from tankbed sediments near Chitradurga town, Karnataka (Shankar et al 2006), has also been associated with our data. Reconstruction of monsoon precipitation using oxygen isotope ratio of annually resolved layers from a speleotheme collected from tropical India (Yadav et al 2004), clearly shows that monsoon rainfall is less from AD 1884 to 1900, somewhat similar to our reconstruction. It verifies the validity of the reconstruction of moisture index.

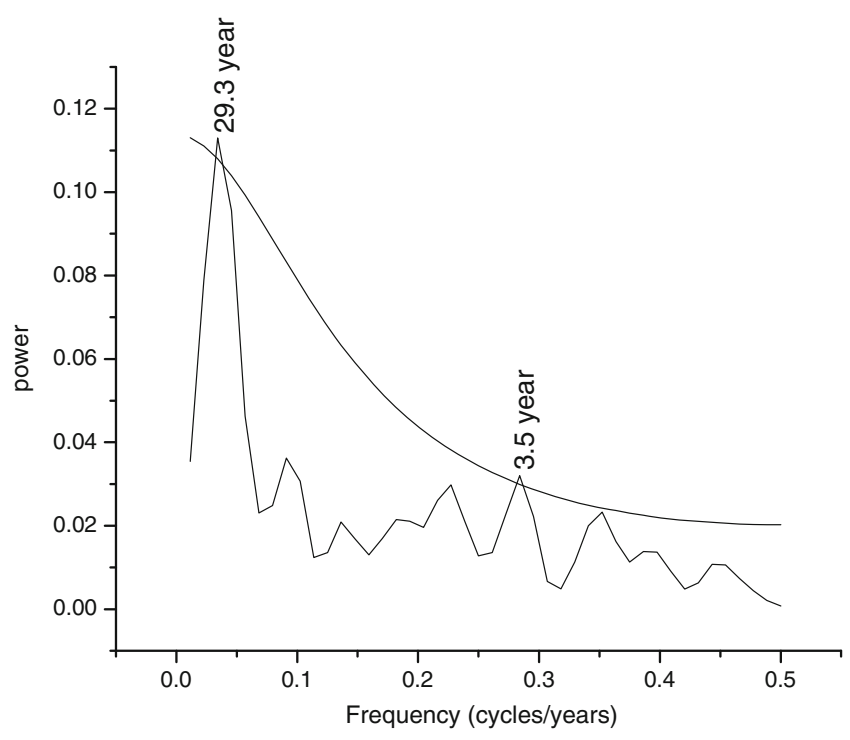

Figure 6. Power spectrum of the reconstructed previous year post-monsoon $(-\mathrm{ON})$ moisture index. Curve is significant at $5 \%$ level. 
The relationship between teak tree-ring chronology and the climate discussed here reveals that moisture index in comparison to rainfall of the region has an important role in the development of annual growth-rings over the region.

To understand the variability modes in the reconstructed moisture index data, we performed spectral analysis over the entire reconstructed time series. Some cycles have been derived from the reconstructed series by following the method of Blackman and Tukey (1958). The analysis indicated significant low frequency peaks at 29.3 years whereas high frequency peaks occurred at 3.5 years, which is significant at 5\% level (figure 6). Variability modes presents in the reconstructed data are found in the EL NiñoSouthern Oscillation (ENSO: 2-8 years) and Pacific Decadal Oscillation (PDO; 20-30 years) frequency domains. Earlier precipitation reconstruction from the Himachal Pradesh also showed a 2-4 years and 20-30 years variability mode (Singh et al 2009). This variability mode is similar with the global phenomena.

The present tree-ring records which extend back to AD 1866 are not enough for the long climatic reconstruction. This shows that the network of tree-ring data developed from the homogeneous sites should result in understanding of climate features over the region. Such long-term data will help in understanding the natural climate variability during the past several hundred years. However, the reconstruction providing a preliminary glimpse of moisture variability has revealed annual to multi-year episodes of wet and dry periods. The significant periodicities noted in the reconstructed series are of 3.5 and 29.3 years.

\section{Acknowledgments}

The authors are thankful to Prof. B N Goswami, Director, IITM, Pune, and Dr N Singh, Head, $\mathrm{C}$ \& $\mathrm{H}$ division, IITM, Pune for the encouragement while carrying out this work. Authors also thank Forest Department, Maharashtra, for providing facilities for collecting samples from remote forest which otherwise could not have been possible. They are grateful to India Meteorological Department for providing the meteorological data. The work was carried out under the ISRO-GBP project funding.

\section{References}

Alley W M 1984 Palmer drought severity index: Limitations and assumptions; J. Clim. Appl. Meteorol. 23 1100-1109.
Bhattacharyya A, Yadav R R, Borgaonkar H P and Pant G B 1992 Growth-ring analysis of Indian tropical trees: Dendroclimatic potential; Curr. Sci. 62 736-741.

Bhattacharyya A and Yadav R R 1999 Climatic reconstruction using tree-ring data from tropical and temperate regions of India - A review; IAWA 20 311-316.

Bhattacharyya A, Eckstein D, Shah S K and Chaudhary V 2007 Analysis of climatic change around Perambikulum, South India, based on early wood mean vessel area of teak; Curr. Sci. 93(8) 1159-1164.

Biondi F and Waikul K 2004 Dendroclim2002: AC++ program for statistical calibration of climate signals in tree-ring chronologies; Comput. Geosci. 30 303-311.

Blackman R B and Tukey J W 1958 The measurement of power spectra (New York, U.S.A.: Dover Publication) $190 p$ p.

Borgaonkar H P, Pant G B and Rupa Kumar K 1994 Dendroclimatic reconstruction of summer precipitation of Srinagar, Kashmir, India since the late 18th Century; Holocene 4 299-306.

Borgaonkar H P, Pant G B and Rupa Kumar K 1996 Ring-width variations in Cedrus deodara and its climatic response over the western Himalaya; Int. J. Climatol. 16 1409-1422.

Borgaonkar H P, Sikder A B, Ram S and Pant G B 2010 El Nino and related monsoon drought signals in 523year-long ring width records of teak (Tectona grandis L.F.) trees from south India; Palaeogeogr. Palaeoclimatol. Palaeoecol. 285 74-84.

Briffa K R, Jones P D and Schweingruber F H 1988 Summer temperature pattern over Europe: A reconstruction from 1750 AD based on maximum latewood density indices of conifers; Quat. Res. 30 36-52.

Buckley B M, Barbette M, Watanasak M, D'Arrigo R, Boonchirdchoo S and Saratunon S 1995 Dendrochronological investigations in Thailand; IAWA $J \mathbf{1 6}$ 393-409.

Buckley B M, Tongjit O, Pumijumnong N and Poonsri R 2001 Dendrometer band studies on Tectona grandis in northern Thailand; Palaeobotanist 50(1) 83-87.

Buckley B M, Cook B I, Bhattacharyya A, Dupka D and Chaudhary V 2005 Global surface temperature signals in pine ring-width chronologies from southern monsoon Asia; Geophys. Res. Lett. 32 L20704, doi: 10.1029/2005GL023745.

Buckley B M, Palkit K, Duangsathaporn K, Sanguantham P and Prasomsin P 2007 Decadal scale droughts over northwestern Thailand over the past 448 years: Link to the tropical Pacific and Indian Ocean sectors; Clim. Dyn., doi: 10.1007/s00382-007-0225-1.

Cook E R, Briffa K, Shiyatov S and Mazepa V 1990 Tree-ring standardization and growth-trend estimation; In: Method of Dendrochronology (eds) Cook E R and Kairiukstis L A (Dordrecht, The Netherland: Kluwer Academic Publishers) 104-123.

Cook E R, Briffa K and Jones P D 1994 Spatial regression methods in dendroclimatology: A review and comparison of two techniques; Int. J. Climatol. 14 379-402, doi: 10.1002/joc.3370140404.

Cook E R, Meko D M, Stahle D W and Cleaveland M K 1999 Drought reconstructions for the continental United States; J. Clim. 12 1145-1162.

Cook E R, Woodhouse C A, Eakin C M, Meko D M and Stahle D W 2004 Long-term aridity changes in the western United States; Science 306 1015-1018.

Dai A, Trenberth K E and Qian T 2004 A global dataset of Palmer Drought Severity Index for 1870-2002: Relationship with soil moisture and effects of surface warming; J. Hydrometeorol. 5 1117-1130. 
D'Arrigo R, Barbetti M, Watanasak M, Buckley B M, Krusic P J, Boonchirdchoo S and Sarutanon S 1997 Progress in dendroclimatic studies of Mountain pine in Northern Thailand; IAWA J 18(4) 433-444.

D'Arrigo R D, Jacoby G and Krusic P 1994 Progress in dendroclimatic studies in Indonesia; Terr. Atmos. Oceanic. Sci. 5 349-363.

D'Arrigo R, Wilson R, Palmer J, Krusic P, Curtis A, Sakulich J, Bijaksana S, Zulaikah S and Ngkoimani L O 2006 Monsoon drought over Java, Indonesia, during the past two centuries; Geophys. Res. Lett. 33 L04709, doi: 10.1029/2005GL025465.

Fritts H C 1976 Tree-rings and Climate; Academic Press, London.

Holmes R L 1983 Computer assisted quality control in tree-ring dating and measurement; Tree-ring Bull. 44 69-75.

Holmes R L, Adams R K and Fritts H C 1986 Treering chronologies of western North America: California, eastern Oregon and northern Great basin with procedure used in the chronology development work including User's Manual for computer programs COFECHA and ARSTAN; Laboratory of Tree Ring Research, University of Arizona, Tucson, Ariz. Chronology Ser. 6.

Keyantash J and Dracup J A 2002 The quantification of drought: An evaluation of drought indices; Bull. Amer. Meteorol. Soc. 83 1167-1180.

Managave S R, Sheshshayee M S, Borgaonkar H P and Ramesh R 2010 Past-break monsoon conditions detectable by high resolution intra-annual $\delta^{18} \mathrm{O}$ analysis of teak rings; Geophys. Res. Lett. 37 L05702, doi:10. 1029/2009GL041172.

Mooley D A and Pant G B 1981 Drought in India over the last 200 years, their socio-economic impacts and remedial measures for them; In: Climate and History, Studies in past climate and their impacts on man (eds) Wigley T M L, Ingram M J and Farmer G (Cambridge, London: Cambridge University Press) 465-478.

Munot A A 1998 Tropical general circulation and its association with the Indian summer monsoon; Ph.D Thesis, University of Pune, Pune, India.

Palmer W C 1965 Meteorological drought; Research paper 45 U.S. Dept. of Commerce, pp. 58.

Pant G B and Borgaonkar H P 1983 Growth rings of teak trees and regional climatology (an ecological study of Thane region); In: Environmental Management (eds)
Singh L R, Singh S, Tiwari R C and Srivastava R P, Geographical Society, Allahabad, India, 153-158.

Pant G B and Borgaonkar H P 1984 Growth rate of Chir pine (pinus roxburghii) trees in Kumaun area in relation to regional climatology; Himalayan Res. Dev. 3 1-5.

Pumijumnong N, Eckstein D and Sass U 1995 Tree-ring research on Tectona grandis in northern Thailand; IAWA 16 385-392.

Ram S, Borgaonkar H P and Sikder A B 2008 Tree-ring analysis of teak (Tectona grandis L.F.) in central India and its relationship with rainfall and moisture index; $J$. Earth Syst. Sci. 117(5) 637-645.

Ram S, Borgaonkar H P and Sikder A B 2010 Varying strength of the relationship between tree-rings and summer month moisture index (April-September) over central India: A case study; Quat. Int. 212 70-75.

Ram S, Borgaonkar H P and Sikder A B 2011 Growth and climate relationship in teak trees from Conolly's plot, South India; Curr. Sci. 100(5) 630-633.

Ramesh R, Bhattacharyya S K and Pant G B 1989 Climatic significance of $\delta \mathrm{D}$ variations in a tropical trees species from India; Nature 337 149-150.

Shah S K, Bhattacharyya A and Chaudhry V 2007 Reconstruction of June-September precipitation based on treering data of teak (Tectona grandis L.) from Hoshangabad, Madhya Pradesh, India; Dendrochronologia 25 57-64.

Shankar R, Prabhu C N A, Warrier K, Vijaya Kumar G T and Sekar B 2006 A multi-decadal rock magnetic record of monsoonal variations during the past 3700 years from a tropical Indian tank; J. Geol. Soc. India 68 447-459.

Singh J, Yadav R R and Wilmking M 2009 A 694-year treering based rainfall reconstruction from Himachal Pradesh, India; Clim. Dyn., doi: 10.1007/s00382-009-0528-5.

Stokes M A and Smiley T L 1968 An introduction to tree-ring dating; University of Chicago Press.

Wigley T M L, Briffia K R and Jones P D 1984 On the average value of correlated time series, with applications in dendroclimatology and hydrometeorology; J. Clim. Appl. Meteorol. 23 201-213.

Yadav R R and Bhattacharyya A 1996 Biological inferences from the growth climate relationship in teak from India; Proc. Indian Acad. Sci., Part B 62 233-238.

Yadav M G, Ramesh R and Pant G B 2004 Past monsoon rainfall variations in peninsular India recorded in a 331year old speleotheme; Holocene 14 517-524. 